\title{
GAS TURBINE AND SENSOR FAULT DIAGNOSIS WITH NESTED ARTIFICIAL NEURAL NETWORKS
}

\author{
N. Xiradakis Y.G. Li \\ School of Engineering, Cranfield University, Bedford MK43 OAL, ENGLAND
}

\section{ABSTRACT}

Accurate gas turbine diagnosis relies on accurate measurements from sensors. Unfortunately, sensors are prone to degradation or failure during gas turbine operations. In this paper a stack of decentralised artificial neural networks are introduced and investigated as an approach to approximate the measurement of a failed sensor once it is detected. Such a system is embedded into a nested neural network system for gas turbine diagnosis. The whole neural network diagnostic system consists of a number of feedforward neural networks for engine component diagnosis, sensor fault detection and isolation; and a stack of decentralised neural networks for sensor fault recovery. The application of the decentralised neural networks for the recovery of any failed sensor has the advantage that the configuration of the nested neural network system for engine component diagnosis is relatively simple as the system does not take into account sensor failure. When a sensor fails, the biased measurement of the failed sensor is replaced with a recovered measurement approximated with the measurements of other healthy sensors. The developed approach has been applied to an engine similar to the industrial 2-shaft engine, GE LM2500+, whose performance and training samples are simulated with an aero-thermodynamic modelling tool - Cranfield
University's TURBOMATCH computer program. Analysis shows that the use of the stack of decentralised neural networks for sensor fault recovery can effectively recover the measurement of a failed sensor. Comparison between the performance of the diagnostic system with and without the decentralised neural networks shows that the sensor recovery can improve the performance of the neural network engine diagnostic system significantly when a sensor fault is present.

\section{KEYWORDS}

Gas Turbine, Sensor, Diagnostics, nested neural networks

\section{NOMENCLATURE}

BR Bayesian Regularization

CF Compressor fault

CTF Compressor turbine fault

DNN Decentralised Neural Network

E Mean Square Error

FFNN Feedforward Neural Network

$M \quad$ Number of training samples

$N \quad$ Number of measurements; Engine

$P_{c} \quad$ Compressor exit total pressure (atm) 


$\begin{array}{ll}P_{e} & \text { Exhaust gas total pressure (atm) } \\ \text { PTF } & \text { Power turbine fault } \\ \text { SCG } & \text { Scaled Conjugate Gradient } \\ \text { s.d. } & \text { Standard deviation } \\ \text { Tansig } & \text { Tangent sigmoid } \\ T_{e} & \text { Exhaust gas total temperature }(\mathrm{K}) \\ T_{c} & \text { Compressor exit total temperature }(\mathrm{K}) \\ W & \text { Flow capacity } \\ W_{f} & \text { Fuel flow rate }(\mathrm{kg} / \mathrm{s}) \\ Y & \text { Network's actual response } \\ Z & \text { Actual value of a parameter } \\ Z_{\text {baseline }} & \text { Baseline value of a parameter } \\ \Delta Z & \text { Normalized deviation }(\%) \\ \eta & \text { Efficiency }\end{array}$

\section{INTRODUCTION}

Gas turbine components, such as compressors and turbines, usually operate in harsh environments and are bound to degrade during their operations. The component degradation will lead to overall engine performance change, which causes the engine to operate in a noneconomical manner or even results in a total failure.

According to Diakunchak [2], about 70 to 80 per cent of gas turbine engine performance loss accumulated during operation is attributed to compressor fouling, turbine erosion and corrosion. Although the degradations have different causes, they all result in a loss of engine performance.

Effective operation of an engine diagnostic system relies on correct information from sensors but sensors may fail within a hostile working environment. Different sensor fault detection techniques have been developed in the past, such as those using neural networks [7, 9, 15, 16], Gas Path Analysis [5] and Genetic Algorithms [17].

Artificial neural networks have been introduced into gas turbine diagnostics since the late 1980's [3] and different types of neural networks have been used for diagnostic purposes. The most popular neural networks are feed forward back propagation (FFBP) neural networks. Due to the complexity of the problem, nested neural networks have been introduced in gas turbine diagnostics by many researchers such as Ogaji and Singh [14].

When a sensor fails, the engine diagnostic system should respond to the change in order to continue the diagnosis correctly. To do so, the engine diagnostic system either has the capability to detect the failed sensor and only use the measurements from the sensors that are not failed, or still use the same measurements but the measurement corresponding to the failed sensor must be replaced with a recovered measurement approximated with other healthy measurements. Obviously, the engine diagnostic system with the former method is more complicated than that with the latter method. The idea of gas turbine diagnostic system using recovered sensors was described in $[7,9,12,13,16]$.

In this research, a stack of decentralised neural networks are used to recover the measurement of any failed sensor, once it is detected, by using other healthy measurements. These decentralised neural networks are then embedded into a neural network gas turbine diagnostic system. Therefore, the whole diagnostic system has the capability of component fault diagnosis, sensor fault diagnosis and recovery. The proposed system is applied to a model gas turbine engine. Discussions and analysis for some cases of typical sensor and engine component degradations are provided.

\section{GAS TURBINE ENGINE MODEL AND ITS PERFORMANCE SIMULATION}

The model gas turbine engine used for this work is similar to the General Electric industrial engine LM $2500+$. It is a two-shaft engine with one compressor, one burner, one compressor turbine and one power turbine shown in Figure 1. The basic performance parameters of the model engine are as follows:

Total pressure ratio:

Turbine Entry Temperature: $1527 \mathrm{~K}$

Mass flow rate: $\quad 86.4 \mathrm{~kg} / \mathrm{s}$

Shaft Power: $29 \mathrm{MW}$

Thermal efficiency: $\quad 38.11 \%$

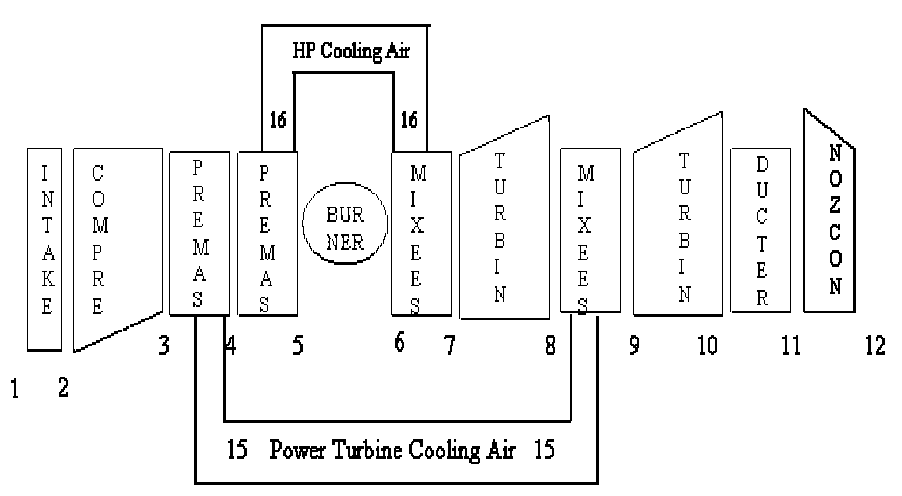

Figure 1 - Schematic illustration of model engine

The performance of the engine is simulated using TURBOMATCH [10], an aero-thermodynamic modelling 
software developed by Cranfield University. TURBOMATCH has been developed and used for many years at Cranfield and has proved a reliable performance simulation tool.

The most common engine degradations, such as compressor fouling, turbine erosion and corrosion, are considered in this study. It is assumed that only a single component fault could be present in the engine at a time. By using TURBOMATCH, different compressor fouling are simulated by reducing its flow capacity and isentropic efficiency by $0.5 \%$ to $6 \%$. Different compressor turbine and power turbine erosions and corrosions are simulated by increasing their flow capacity by $0.5 \%$ to $6 \%$ and reducing their isentropic efficiency by $0.5 \%$ to $6 \%$.

Six measurable engine parameters are selected for diagnostic purposes and they are as follows:

- fuel flow rate $\left(W_{f}\right)$

- exhaust gas total temperature $\left(T_{e}\right)$

- exhaust gas total pressure $\left(P_{e}\right)$

- compressor exit total temperature $\left(T_{c}\right)$

- compressor exit total pressure $\left(P_{c}\right)$

- engine relative rotational speed $(N)$

\begin{tabular}{|c|c|c|}
\hline Sensor & $\begin{array}{c}\text { Measurement Noise } \\
\text { (\% of measurement) }\end{array}$ & $\begin{array}{c}\text { Measurement Bias } \\
\text { (\% of measurement) }\end{array}$ \\
\hline$W_{f}, T_{c}, P_{c}$ & $\pm 0.5 \%$ & $\pm 1-6 \%$ \\
\hline$T_{e}$ & $\pm 1 \%$ & $\pm 1.5-4 \%$ \\
\hline$T_{c}$ & $\pm 0.3 \%$ & $\pm 0.6-4 \%$ \\
\hline$N$ & $\pm 0.1 \%$ & $\pm 0.3-3 \%$ \\
\hline
\end{tabular}

Table 1. Level of measurement noise and bias

Measurements from the clean and degraded model engine are simulated with TURBOMATCH. These measurements are subject to measurement errors that can be expressed as measurement noise and bias. In order to make the investigation more realistic, all the simulated measurements are superimposed with a level of random measurement noise. The maximum measurement noise levels for different measurable parameters are assumed and shown in Table 1. Sensor degradation is simulated by superimposing a bias on the corresponding simulated measurement. Table 1 also shows the levels of the biases that are used to simulate sensor failure.

Different component degradations are implanted in the model engine with TURBOMATCH to produce a large number of training samples inclusive of measurement noise. Measurement biases are included in the simulated measurements to simulate different cases of degraded sensors.

\section{ARTIFICIAL NEURAL NETWORKS FOR ENGINE AND SENSOR DIAGNOSIS}

\section{Feed forward neural networks}

The most commonly used artificial neural networks for gas turbine diagnosis are the Feed Forward Neural Networks (FFNN) and they are used in this study. FFNNs have been used by many researchers for the detection, isolation and quantification of gas turbine component faults [8].

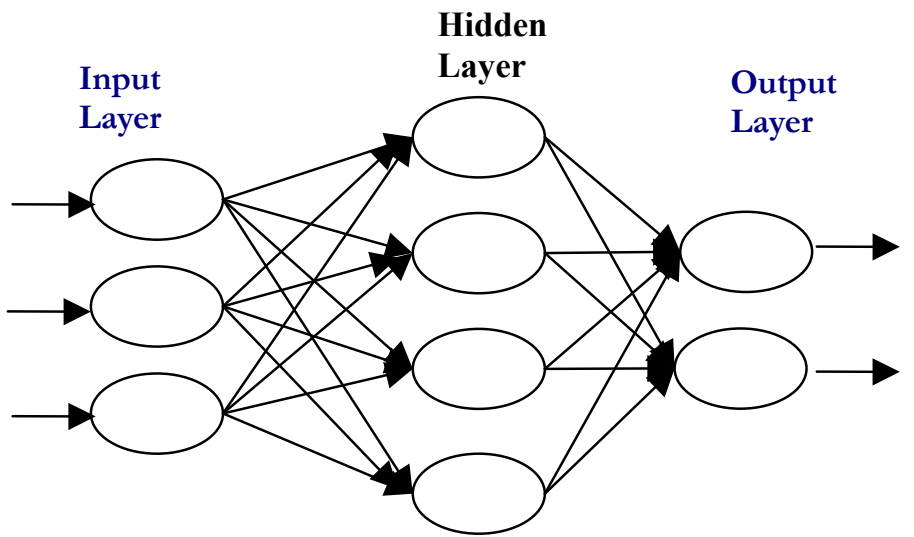

Figure 2. A typical FFNN

A typical FFNN that consists of a hidden layer is shown in Figure 2. A FFNN normally consists of an input layer of source nodes, one or more hidden layers and an output layer. The function of the hidden layers is to intervene between the input layer and the output layer. Non-linear activation functions, such as the hyperbolic tangent sigmoid function, are used to take into account the non-linear relationship between the input and the output of the neural network.

\section{Decentralised neural networks}

Decentralised Neural Networks (DNN) have been used in the past by researchers such as Napolitano et al. $[12,13]$ and $\mathrm{Lu}$ and Hsu [9] for the approximation of sensor faults. A DNN is basically a FFNN. Its input layer consists of $n-k$ nodes and its output layer of $k$ nodes, where $n$ is the total number of sensors and $k$ the number of sensors failed. In this research, it is assumed that only one sensor may fail at a time so $k=1$. Such a network system configuration gives the system the ability to approximate the measurement of a failed sensor by using 
the information from other sensors that are working correctly. Usually the same of number of DNNs to that of the sensors is used so that the measurement of any failed sensor can be recovered.

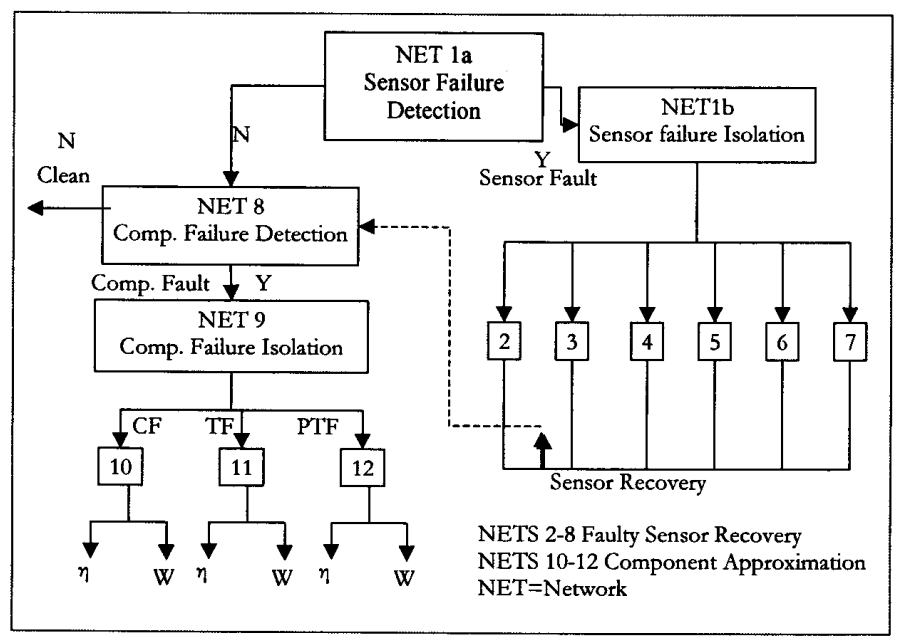

Figure 3. Nested neural networks

\section{Neural network diagnostic system}

A single neural network, whatever its type is, cannot cope with the complexity of real problems such as gas turbine component and sensor diagnosis. Therefore, a nested neural network system is needed. Such a system consists of a number of different neural networks; each one of them is trained for a particular job.

The configuration of the nested neural network diagnostic system and how the system works are shown in Figure 3. Within the system, Net 1a, a FFNN used for the detection of a sensor fault, receives measurement data from the gas turbine engine and starts the diagnostic process. If a sensor fault is detected the measurement data is passed to Net $1 \mathrm{~b}$ that is also a FFNN used to isolate the particular sensor that is faulty. When the faulty sensor is isolated, the data is fed to one of the six decentralised neural networks (Nets 2-7) corresponding to the six sensors that have been used. Each one of Nets 2-7 is capable of approximating the correct output of the sensor when it works properly. The recovered sensor value together with other sensor values is then fed into Net 8 for engine component diagnostic analysis.

If Net 1a does not detect any sensor fault, the measurement data is fed into Net 8 that is able to identify if there is a component fault. If there is no component fault, the engine is declared being clean then the diagnostic process finishes. If there is a component fault the measurement data is passed to Net 9 that detects which component has the fault, i.e. the compressor (CF), the compressor turbine (CTF) or the power turbine (PTF). Following Net 9 are Nets 10-12 that can quantify the fault in terms of the change in isentropic efficiency $\eta$ and flow capacity $W$ of the components. Nets 8-12 are all of the feed forward type.

\section{Training of nested neural networks}

The neural networks should be trained with training samples and validated with validation samples before they can be used for engine and sensor diagnosis. The training and validation samples are simulated with TURBOMATCH by implanting different component and sensor faults.

Since the six sensors are used to measure different engine parameters, each one of them would have a completely different range. Therefore, the training and validation samples are normalised so that they all fall into the same range in order that the neural networks can be trained and validated properly. The equation used for the normalization is shown below:

$$
\Delta Z=\frac{Z-Z_{\text {baseline }}}{Z_{\text {baseline }}} \times 100
$$

where $Z$ is the value of a parameter and $Z_{\text {baseline }}$ an established baseline value for the parameter.

The activation function used for all nodes is the hyperbolic tangent sigmoid transfer function (tansig). It squashes all inputs to give output in the range $\{-1,1\}$. The networks are trained using batch training and supervised learning. The training algorithm is the Scaled Conjugate Algorithm (SCG). The SCG training algorithm is chosen as it performs well over a wide variety of problems and has relatively modest memory requirements compared to other algorithms such as LavenbergMarquardt. [1]. A full description of the SCG training algorithm can be found in $[6,11]$.

Having decided on all the above, the next step is the actual training and validation of the neural networks. Neural networks with different architectures are trained and validated until acceptable results are obtained. The performance of the networks is assessed by two criteria, the Mean Square Error $(E)$ and the generalization of the validation data set.

The Mean Square Error function is given by Equation 2

$$
E=\frac{1}{N} \sum_{k=1}^{M} \sum_{i=1}^{N}\left(Y_{k i}-Z_{k i}\right)^{2}
$$

where $M$ is the number of training patterns and $N$ the number of measurements, $Z_{k i}$ are the target values and 
$Y_{k i}$ the network's responses. In theory the training process should reduce the Mean Square Error $E$.

The generalization of a network is defined as the ability of the network to produce the outputs that are close to their target values.

The details of the training of the 13 networks in the nested neural network system (Figure 3 ) are discussed as follows.

\section{Net 1a}

Net 1a is a FFNN network used to detect if there is a sensor fault. The training and validation samples include cases for a clean engine and a degraded engine with different component and sensor degradations. A summary of the training results and the performance of Net 1a is shown in Table 2. Assessed with the validation samples, Net $1 \mathrm{a}$ is able to classify around $95.67 \%$ of the patterns correctly.

\begin{tabular}{|c|c|c|}
\hline \multicolumn{2}{|c|}{ Architecture } & $6-20-20-2$ \\
\hline \multicolumn{2}{|c|}{ Number of training samples } & 8786 \\
\hline \multicolumn{2}{|c|}{ Number of validation samples } & 8786 \\
\hline \multicolumn{2}{|c|}{ Mean Square Error } & 0.0631 \\
\hline \multicolumn{2}{|c|}{ Epochs } & 1751 \\
\hline \multicolumn{2}{|c|}{ Time } & $25 \mathrm{~min}$ \\
\hline \multirow{2}{*}{$\begin{array}{l}\text { Correctly Detected } \\
\text { Patterns }\end{array}$} & Training (\%) & 96.70 \\
\hline & Validation (\%) & 95.67 \\
\hline \multicolumn{2}{|c|}{ Faults Categorized as No Faults (\%) } & 1.86 \\
\hline \multicolumn{2}{|c|}{ No Faults Categorized as Faults (\%) } & 2.47 \\
\hline
\end{tabular}

Table 2. Details of Net 1a

\begin{tabular}{|c|c|c|}
\hline \multicolumn{2}{|c|}{ Architecture } & $6-12-12-6$ \\
\hline \multicolumn{2}{|c|}{ Number of training samples } & 5024 \\
\hline \multicolumn{2}{|c|}{ Number of validation samples } & 5024 \\
\hline \multicolumn{2}{|c|}{ Mean Square Error } & 0.0845 \\
\hline \multicolumn{2}{|c|}{ Epochs } & 1351 \\
\hline \multicolumn{2}{|c|}{ Time (min) } & 15 \\
\hline \multirow{2}{*}{$\begin{array}{l}\text { Correctly Isolated } \\
\text { Patterns (\%) }\end{array}$} & Train \%. & 92 \\
\hline & Valid \%. & 85 \\
\hline
\end{tabular}

Table 3. Details of Net $1 \mathrm{~b}$

\section{Net $1 b$}

Net $1 b$ is used for the isolation of a faulty sensor. The training and validation samples for this network is the same as those for Net 1a, Table 2. The only difference is that the training and validation samples for the clean engine and the degraded engine with different component degradations are excluded.
The training results and the performance of Net $1 \mathrm{~b}$ are shown in Table 3. The performance of Net $1 \mathrm{~b}$ is not as good as that of Net 1a. This is because the task of Net $1 \mathrm{~b}$ is more complicated than that of Net 1a in the sense that it is to classify the data into six categories, one for each sensor. Assessed with the validation samples, Net $1 \mathrm{~b}$ can predict about $85 \%$ of the fault patterns correctly.

\section{Nets 2 to 7}

Nets 2 to 7 are all decentralised neural networks for faulty sensor fault recovery and they have the same architecture. The inputs to these networks are the measurements from all sensors except the one detected as faulty. The outputs of these networks are the recovered measurements corresponding to the failed sensors. Therefore only one of them, Net 5 for the approximation of the measurement of the compressor exit temperature $\left(\mathrm{T}_{\mathrm{c}}\right)$, is presented.

\begin{tabular}{|c|c|c|}
\hline \multicolumn{2}{|c|}{ Architecture } & $5-20-20-1$ \\
\hline \multicolumn{2}{|c|}{ Number of training samples } & 4524 \\
\hline \multicolumn{2}{|c|}{ Number of validation samples } & 4524 \\
\hline \multicolumn{2}{|c|}{ Mean Square Error } & 0.0008 \\
\hline \multicolumn{2}{|c|}{ Epoch } & 1351 \\
\hline \multicolumn{2}{|c|}{ Time } & $10 \mathrm{~min}$ \\
\hline \multicolumn{2}{|c|}{ Threshold } & \pm 0.3 \\
\hline \multirow{2}{*}{$\begin{array}{c}\text { Data within } \\
\text { Threshold (\%) }\end{array}$} & Training & 99.8 \\
\hline & Validation & 99.96 \\
\hline \multicolumn{2}{|c|}{ s.d (Validation) } & 0.0782 \\
\hline \multicolumn{2}{|c|}{ Within 1 s.d (\%) } & 80.17 \\
\hline \multicolumn{2}{|c|}{ Within 2 s.d (\%) } & 96.31 \\
\hline \multicolumn{2}{|c|}{ Within 3 s.d (\%) } & 99.27 \\
\hline
\end{tabular}

Table 4. Details of Nets 5

The training results and the performance of Net 5 are shown in Table 4. The performance of the network is judged based on the percentage deviation of the output from the desired output. If the predicted percentage deviation is within the established noise level, the estimation is declared to be successful. The threshold is taken to be the maximum noise level for the parameter defined in Table 1.

Net 5 performs very well (Table 4). Nearly $100 \%$ of the training and the validation patterns are estimated within the predefined threshold. The distribution of the prediction errors of Net 5 is fairly normally and narrowly distributed (Figure 4). 


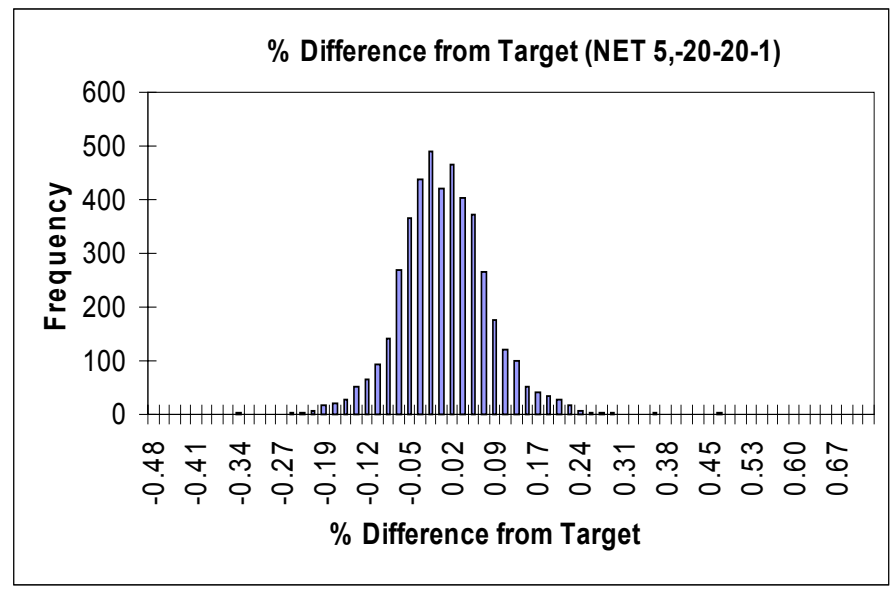

Figure 4. Percentage difference from target (Net 5)

All the other decentralised networks have similar performance compared to Net 5 except Net 7 . Net 7 is used for the recovery of the rotational speed $(\mathrm{N})$. The low percentage of successful fault prediction of Net 7 is due to its low threshold compared to other decentralised networks. A performance comparison among Nets 2-7 is shown in Table 7.

\section{Nets 8 and 9}

Net 8 is used to detect whether there is an engine component fault. The input to the network is the measurements from the six sensors. The output from the network is either $[0,1]$ for no fault or $[1,0]$ for a fault.

\begin{tabular}{|c|c|c|c|}
\hline & Net 8 & Net 9 \\
\hline \multicolumn{2}{|c|}{ Architecture } & $6-8-2$ & $6-10-3$ \\
\hline \multicolumn{2}{|c|}{$\begin{array}{c}\text { Number of training } \\
\text { samples }\end{array}$} & 5025 & 3024 \\
\hline \multicolumn{2}{|c|}{$\begin{array}{c}\text { Number of validation } \\
\text { samples }\end{array}$} & 4160 & 3024 \\
\hline \multirow{2}{*}{\multicolumn{2}{|c|}{$\begin{array}{c}\text { Mean Square Error } \\
\text { Epochs }\end{array}$}} & $4.9^{*} \mathrm{E}-36$ & 0.0810 \\
\hline & & 187 & 651 \\
\hline \multicolumn{2}{|c|}{ Time } & $7 \mathrm{~min}$ & $5 \mathrm{~min}$ \\
\hline \multirow{2}{*}{$\begin{array}{c}\text { Correctly } \\
\text { Detected } \\
\text { or isolated } \\
\text { Patterns }\end{array}$} & Training (\%) & 100 & 98.62 \\
\hline & $\begin{array}{l}\text { Validation } \\
\qquad(\%)\end{array}$ & 99.86 & 96.59 \\
\hline
\end{tabular}

Table 5. Details of Nets 8 and 9

Net 9 is used to isolate a particular component that is faulty. When a faulty component is detected, the value of the output node corresponding to the faulty component is 1 while the values of the nodes for other components are all 0 . An example of the output is $[0,1,0]$ pointing to a compressor turbine fault.
The training results and the performance of the two networks are shown in Table 5. It can be seen that after training the percentage of correctly detected patterns is $99.86 \%$ for Net 8 and $96.59 \%$ for Net 9 using the validation samples, which are very good results.

\begin{tabular}{|c|c|c|}
\hline \multicolumn{2}{|c|}{ Architecture } & $6-20-2$ \\
\hline \multicolumn{2}{|c|}{ Number of training samples } & 1008 \\
\hline \multicolumn{2}{|c|}{ Number of validation samples } & 1008 \\
\hline \multicolumn{2}{|c|}{ Mean Square Error } & 0.0011 \\
\hline \multicolumn{2}{|c|}{ Epochs } & 5000 \\
\hline \multicolumn{2}{|c|}{ Time } & $25 \min$ \\
\hline \multirow{2}{*}{$\begin{array}{l}\text { s.d (Isentropic } \\
\text { Efficiency) }\end{array}$} & training & 0.0750 \\
\hline & validation & 0.0939 \\
\hline \multirow{2}{*}{$\begin{array}{l}\text { s.d (Flow } \\
\text { Capacity) }\end{array}$} & training & 0.1050 \\
\hline & validation & 0.1572 \\
\hline \multirow{3}{*}{$\begin{array}{l}\text { Validation \% Data } \\
\text { within (Isentr. Eff.) }\end{array}$} & 1 s.d. & 87 \\
\hline & 2 s.d. & 99 \\
\hline & 3 s.d. & 100 \\
\hline \multirow{3}{*}{$\begin{array}{c}\text { Validation \% Data } \\
\text { within (Flow } \\
\text { Capacity) }\end{array}$} & 1 s.d. & 97 \\
\hline & 2 s.d. & 99 \\
\hline & 3 s.d. & 100 \\
\hline
\end{tabular}

Table 6. Summary of Net 11

\begin{tabular}{|c|c|c|c|}
\hline Net & $\begin{array}{c}\text { Selected } \\
\text { Architecture }\end{array}$ & Threshold & $\begin{array}{c}\text { Correctly } \\
\text { Detected } \\
\text { Patterns (\%) }\end{array}$ \\
\hline $1 \mathrm{a}$ & $6-20-20-2$ & & 96.70 \\
\hline $1 b$ & $6-12-12-6$ & & 85.00 \\
\hline 2 & \multirow{6}{*}{$5-20-20-1$} & \pm 0.5 & 99.18 \\
\hline 3 & & \pm 1.0 & 100.00 \\
\hline 4 & & \pm 0.5 & 99.43 \\
\hline 5 & & \pm 0.3 & 99.96 \\
\hline 6 & & \pm 0.5 & 92.12 \\
\hline 7 & & \pm 0.1 & 63.22 \\
\hline 8 & $6-8-2$ & & 99.98 \\
\hline 9 & $6-10-3$ & & 96.73 \\
\hline 10 & $6-10-2$ & 2 s.d. & 99.00 \\
\hline 11 & $6-20-2$ & 2 s.d. & 99.00 \\
\hline 12 & $6-10-2$ & 2 s.d. & 99.00 \\
\hline
\end{tabular}

\section{Table 7. Performance comparison of all networks}

\section{Nets 10 to 12}

Nets 10 to 12 are used to approximate the level of degradation of the three components in terms of their change in isentropic efficiencies and flow capacities. 
These three networks deal with similar problems and have a similar architecture so only Net 11 is discussed.

The training results and the performance of Net 11 are shown in Table 6. Assessed with the validation samples, it can be seen that the values of standard deviations (s.d.) are small so the network is capable of predicting the faults with a high level of accuracy. If 2 s.d is used as a threshold to assess the performance of the network, Net 11 has the potential to correctly predict the degradation by $99 \%$. Both Nets 10 and 12 give very similar results to Net 11 .

A comparison of the performance of all the neural networks within the whole diagnostic system (Figure 3 ) is shown in Table 7.

\section{DISCUSSIONS AND ANALYSIS}

Once the training process for the nested neural networks is finished, the neural network diagnostic system is ready for the detection, isolation and recovery of any faulty sensor as well as the diagnosis and assessment of engine component faults.

The overall performance of the network system is the combination of the performance of individual networks. Therefore, the percentage of correctly detected fault patterns of the whole diagnostic system is the multiplication of the percentages of correctly detected fault patterns of individual networks in use. To see the performance of the whole diagnostic system, analysis is carried out for some engine and sensor fault cases as follows.

\section{Case 1:}

The diagnostic system receives measurement information from the engine in Net 1a that has a percentage of correct classification of about $95.67 \%$ and a percentage of no-faults classified as faults of about $2.47 \%$. When a sensor fault occurs and is wrongly declared, Net $1 \mathrm{~b}$ is going to indicate a sensor fault and pass the measurement data to a selected network in Nets 2-7. The selected network will provide an estimate of the measurement of the declared faulty sensor. The estimate of the measurement of the declared faulty sensor should be very close to its original value as the sensor is not faulty. Therefore, the diagnostic procedure will continue without any problem by feeding the measuremeent data into Net 8. Because of the existence of the decentralised neural networks, the performance of Net 1a can be improved by $2.47 \%$, i.e. from $95.67 \%$ to $98.14 \%$.
Case 2:

The performance of the engine diagnostic system (Nets 8-12) is analysed with and without the 6 decentralized neural networks, Nets 2-7, when combined component and sensor faults are presented. For this purpose simulated measurements for some typical combined component and sensor faults are created and passed to the neural network diagnostic system. The test cases that are used are summarized in Table 8.

\begin{tabular}{|c|c|c|}
\hline Type & Faults & $\begin{array}{c}\text { Number of } \\
\text { Fault Cases }\end{array}$ \\
\hline 1 & $\begin{array}{c}\text { Compressor Fault combined } \\
\text { with Sensor Faults }\end{array}$ & 10 \\
\hline 2 & $\begin{array}{c}\text { Turbine Fault combined with } \\
\text { Sensor Faults }\end{array}$ & 10 \\
\hline 3 & $\begin{array}{c}\text { Power Turbine Fault } \\
\text { combined with Sensor Faults }\end{array}$ & 10 \\
\hline 4 & $\begin{array}{c}\text { Clean engine combined with } \\
\text { Sensor Faults }\end{array}$ & 10 \\
\hline \multicolumn{2}{|c|}{ Total } & 40 \\
\hline
\end{tabular}

Table 8. Data used for testing

First the simulated measurements of fault cases in Table 8 are fed into Net 8 . In the test Net 8 successfully classifies the fault patterns by $100 \%$. Then all the data are fed into Net 9 that has the potential to correctly classify $96.73 \%$ of the faults using bias free measurements. The test shows that without the decentralized networks the percentage of correctly detected fault patterns of Net 9 falls to $63.33 \%$.

\begin{tabular}{|c|c|c|c|c|}
\cline { 3 - 5 } \multicolumn{2}{c|}{} & $\begin{array}{c}\text { Net 10 } \\
(6-10-2)\end{array}$ & $\begin{array}{c}\text { Net 11 } \\
(6-20-2)\end{array}$ & $\begin{array}{c}\text { Net 12 } \\
(6-10-2)\end{array}$ \\
\hline $\begin{array}{c}\% \text { of Errors } \\
\text { inside the } \\
\text { pre-defined } \\
\text { threshold }\end{array}$ & $\begin{array}{c}\text { Isentropic } \\
\text { Efficiency }\end{array}$ & 10 & 10 & 40 \\
\cline { 3 - 5 } & Flow Capacity & 0 & 20 & 60 \\
\hline
\end{tabular}

Table 9. Performance of Nets 10, 11 and 12 when Nets 2-7 are absent

Suppose that Nets 8 and 9 provide correct detection and isolation of the component faults for the test cases then the measurement data are passed to one of Nets 1012 for the estimation of the component degradation. The prediction errors that are the difference between the predicted degradations and the implanted degradations are compared with predefined thresholds taken to be $3^{*}$ s.d. The success of the predictions is judged by whether the prediction errors are within the thresholds. Table 9 
shows the results. It can be seen that the prediction accuracy is fairly low.

\section{Case 3:}

The influence of the performance of individual neural networks on the performance of the whole diagnostic system can be seen in the following analysis.

When the compressor turbine degrades without sensor fault, the percentage of correctly quantified faults is around $91.48 \%$ that is obtained by multiplying the percentages of correctly detected fault patterns of Nets 1a, 8,9 and 11 . When a combined compressor turbine fault and sensor $T_{c}$ fault is presented to the diagnostic system, the percentage of correctly detected faults is around $84.12 \%$ that is obtained by multiplying the percentages of correctly predicted fault patterns of Nets $1 \mathrm{a}, 1 \mathrm{~b}, 5,8,9$ and 11 . This relatively low value of the percentage in the latter situation is due to the relatively poor performance of Net $1 \mathrm{~b}$. Even so, the performance of the whole diagnostic system is still much better than that when the decentralised networks are absent, as discussed in Case 2. Therefore, to have a good performance of the whole diagnostic system each of the nested neural networks within the system must have good performance and the sensor fault recovery does improve the performance of the engine diagnostic system when a sensor fault is present.

\section{Case 4:}

For trained neural networks, for example Nets 2-7, their performance is affected by the complexity of the problems they encounter. Nets 2-7 are designed and trained for both sensor faults and combined sensor and component faults. It is found that when the networks are applied to sensor fault cases only, the performance of the networks is much better than that when they are applied to all different fault cases. For example, Net 7 has the percentage of prediction accuracy of only $63.22 \%$ for all fault cases. When it is used for sensor fault cases only, the prediction accuracy of Net 7 can reach to around $91.20 \%$.

\section{CONCLUSIONS}

A nested decentralised neural network system is introduced and embedded into a neural network gas turbine diagnostic system. It has the capability to detect and isolate a failed sensor and provide the engine diagnostic system with an estimated measurement of the failed sensor. Therefore, embedded with the decentralised neural networks, the engine component diagnostic system can get rid of the impact of the sensor bias and ensure the prediction accuracy of the engine component diagnostic system. In addition, the engine component diagnostic system has a relatively simple configuration by not taking into account sensor failure.

The investigation shows that the decentralised neural networks can successfully recover the measurement from a failed sensor by using the remaining sensors that are working properly. The application of sensor fault recovery can improve the performance of fault classification network Net 8 by $2.47 \%$.

Analysis also shows that when a combined component and sensor fault occurs the fault classification accuracy of the component fault classification network Net 9 may fall from $96.73 \%$ with bias free measurements to $63.33 \%$ with biased measurements. The performance of component fault quantification neural networks Nets 10-12 may also fall significantly with biased measurements.

The performance of the whole neural network diagnostic system is determined by the performance of individual networks within the system. To have good neural network diagnostic system, all the neural networks within the system must have good performance.

\section{AKNOWLEDGEMENTS}

The authors would like to thank Prof. P. Pilidis at Cranfield University for his support and Dr. Steven Ogaji for his help during the project.

\section{REFERENCES}

[1] Demuth, H., Beale, M., "Neural Network Toolbox, version 4", The Mathwork Inc

[2] Diakunchak, I. S., "Performance Deterioration in Industrial Gas Turbines", Transactions of the ASME, Journal of Engineering for Gas Turbines and Power, Vol. 114, April 1992, pages 116-168

[3] Dietz W.E., Kiech E.L. and Ali M., "Jet and Rocket Engine Fault Diagnosis in Real Time", J. Neural Network Compt., Vol.1, No.1, pp.5-18, 1989.

[4] Doel, D.L, "An Assessment of Weighted-LeastSquares- Based Gas Path Analysis", Journal for Gas Turbines and Power, Vol. 116, No. 2, April 1994, pages 366-373

[5] Escher P.C., "Gas Turbine Data Validation Using Gas Path Analysis", ASME Paper GT-2002-30024, 2002. 
[6] Foresee, F. D., Hagan, M. T., "Gauss-Newton approximation to Bayesian regularization," In: Proceedings of the 1997 International Joint Conference on Neural Networks, 1997, pages 19301935.

[7] Guo T.-H., Saus J., Lin C.-F. and Ge J.-H., "Sensor Validation for Turbofan Engines Using an Autoassociative Neural Network", AIAA Paper 963926, 1996.

[8] Li Y. G., "Performance-Analysis-Based Gas TURBINE Diagnostics: A Review", IMechE Journal of Power and Energy, Vol.216, No.A5, 2002.

[9] Lu, P. J., Hsu, T. C., "Application of Autoassociative Neural Network on Gas-Path Sensor Validation", Journal of Propulsion and Power, Vol.18, No. 4, July-August 2002, pages 879-888

[10] Macmillan W.L., "Development of a Module Type Computer Program for the Calculation of Gas Turbine Off Design Performance", Ph.D. thesis, Cranfield University, England, 1974.

[11] Moller, M., "A scaled Conjugate Gradient Algorithm For Fast Supervised Learning", WWW Document, http://citeseer.nj.nec.com/ller93scaled.html, (assessed 16 August 2003)

[12] Napolitano, M. R., Neppach, C., Casdorph, V., Naylor, S., "Neural-Network-Based Scheme for Sensor Failure Detection Identification, and Accommodation" Journal of Guidance, Control and Dynamics, Vol.18, No. 6, November-December 1995, pages $1280-1286$

[13] Napolitano, M., Windon, D., Casanova, J., Innocenti, M., " A comparison Between Kalman Filter and Neural Network Approaches For Sensory Validation", AIAA Guidance, Navigation and Control Conference, San Diego CA USA, 29-31 ${ }^{\text {st }}$ July, AIAA paper 96-3894

[14] Ogaji S.O.T. and Singh R., "Gas Turbine Fault Diagnosis Framework for a Three-Shaft Gas Turbine", IMechE Journal of Power and Energy, Vol.217, No.A2, 2002.

[15] Ogaji, S. O. T., Singh, R., Probert, S. D., "Multiplesensor fault-diagnoses for a 2-shaft stationary gas turbine", Applied Energy, Vol. 71, 2002, pages 321339

[16] Huang Weidong, Wang Kechang and Chen Qizhi, "Sensor Failure Detection and Data Recovery Based on Neural Network", AIAA Paper 96-2932, 1996.

[17] Zedda M. and Singh R., "Gas Turbine Engine And Sensor Fault Diagnosis Using Optimisation Techniques", AIAA-99-2530, 1999. 
2004

\title{
Gas turbine and sensor fault diagnosis with nested artificial neural networks
}

\author{
Xiradakis, N
}

ASME

Xiradakis N, Li YG, Gas turbine and sensor fault diagnosis with nested artificial neural networks, Proceedings of ASME Turbo Expo 2004: Power for Land, Sea, and Air, 14-17 July 2004, Vienna, Austria, Volume 7, pp. 351-359, paper number GT2004-53570

http://dx.doi.org/10.1115/GT2004-53570

Downloaded from Cranfield Library Services E-Repository 